\title{
Abrindo mentes com a computação desplugada: uma experiência com meninas de oitavo e nono anos
}

\author{
Julia Passos ${ }^{1}$, Karina Huh ${ }^{1}$, Lais Cavalheiro ${ }^{1}$, Yasmin Gonçalves ${ }^{1}$, \\ Marcelo M. Eler ${ }^{1}$, Josely Cubero ${ }^{1}$ e Sarajane M. Peres ${ }^{1}$ \\ ${ }^{1}$ Universidade de São Paulo \\ São Paulo, SP, Brasil \\ \{juliapassos, karinahuh, laiscarraro, yasminsanches\}@usp.br \\ \{marceloeler, josely, sarajane\}@usp.br
}

\begin{abstract}
The low representativeness of women in the technology field motivates, globally, initiatives to reduce the gender gap in the area. This paper presents the GRACE project, whose purpose is to promote female participation in the Computing field, and discusses its seminal initiative: provide girls of the eighth and ninth grades of elementary school ${ }^{1}$ with information about computing.
\end{abstract}

Resumo. A baixa representatividade feminina na área de tecnologia motiva, globalmente, iniciativas para diminuir a disparidade de gênero na área. Este artigo apresenta o projeto GRACE, cujo objetivo é fomentar a participação feminina na área da Computação, e discute sua iniciativa seminal: levar informação sobre computação para meninas de oitavo e nono anos do ensino fundamental.

\section{Introdução}

A disparidade de gênero entre estudantes e profissionais que atuam nas carreiras das área de Exatas motivou projetos globais para aumentar a participação de mulheres nessas áreas [Cimpian et al. 2020]. Em particular, a desigualdade numérica observada nos cursos superiores da área de Computação no Brasil [Ribeiro et al. 2019] fomentou iniciativas cujo objetivo é aumentar a participação feminina nesses cursos [Nunes et al. 2016]. A maioria das iniciativas do tipo usam atividades como: encontros, painéis, workshops, palestras, cursos de programação e eletrônica, projetos de interfaces humano-computador, atividades de computação desplugada e jogos [Maciel and Bim 2016, Torres et al. 2017, de Santana and Pereira 2019].

No Brasil, outro fator importante também precisa ser considerado quando se trata de desigualdade: a exclusão digital. Acredita-se que alunas do ensino fundamental e médio que possuem menos acesso, ou mais tardio, a tecnologias podem ter menor probabilidade de escolher um curso superior na área da computação. É necessário, portanto, que ações que buscam a paridade de gênero na área de computação levem em consideração os diferentes momentos escolares para ajustar ou priorizar suas estratégias.

Neste contexto, o objetivo deste artigo é apresentar o projeto GRACE, com destaque para o seu esforço em colocar universitárias em contato direto com alunas de oitavo e nono anos do ensino fundamental e, com apoio da computação desplugada, motivar essas alunas a abrirem suas mentes para a possibilidade de seguir uma carreira em Computação.

\footnotetext{
${ }^{1}$ According to the Brazilian Education System
} 


\section{O projeto GRACE}

O projeto GRACE ${ }^{2}$ foi elaborado e é desenvolvido no âmbito do grupo PET-SI ${ }^{3}$. O PET-SI é parte do Programa de Educação Tutorial do Ministério da Educação [Peres et al. 2014] e foi institucionalizado em 2010 junto ao curso de Sistemas de Informação da Universidade de São Paulo. Para a execução do projeto GRACE, o PET-SI conta também com a colaboração de pessoas externas ao grupo.

O projeto GRACE foi criado em 2016 e a Figura 1 resume sua evolução até o momento. No início, as universitárias do PET-SI se aproximaram de iniciativas semelhantes e realizaram um estudo sobre a disparidade de gênero no próprio curso de Sistemas de Informação. Os resultados do estudo estão ilustrados na Figura $2^{4}$ e mostraram que a situação era preocupante, com uma média de $85 \%$ de ingressantes homens contra $15 \%$ de ingressantes mulheres. Após esse levantamento, o grupo transformou a iniciativa em um projeto de extensão universitária para atuar junto a alunas do ensino fundamental.

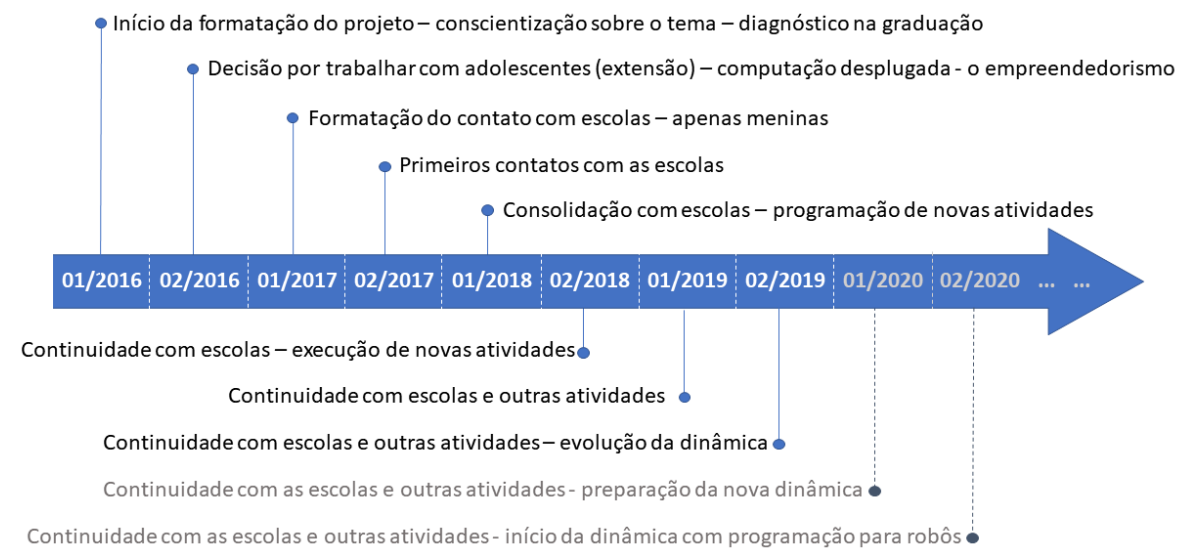

Figura 1. Linha do tempo - projeto GRACE

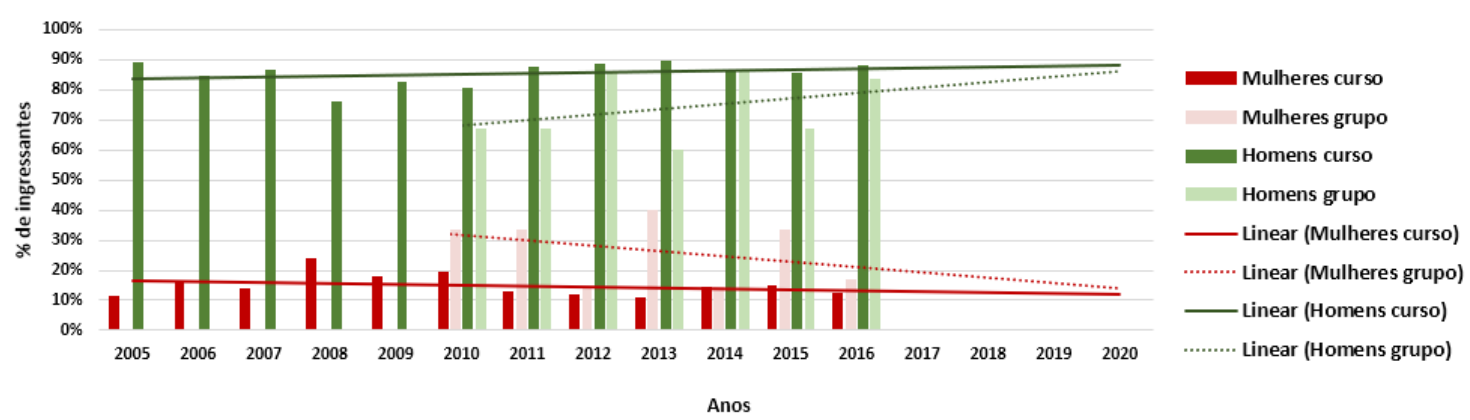

Figura 2. Ingressantes no curso de Sistemas de Informaçãoe no PET-SIpor ano

Em 2017, o projeto GRACE fez os primeiros contatos com as escolas e, em 2018, realizou suas primeiras visitas a escolas. Em 2019, a interação com as escolas e as alunas

\footnotetext{
${ }^{2}$ http://www.each.usp.br/petsi/grace/

${ }^{3}$ http: / / www. each.usp.br/petsi/

${ }^{4}$ Os dados de ingressantes apresentados aqui não são dados oficiais da Universidade de São Paulo e podem conter pequenas distorções referentes a forma como um aluno é computado como ingressante. Há distorções provenientes de dados como re-ingressos, trancamentos e reprovações. Contudo, tais distorções são pequenas o suficiente para serem tratadas como ruído.
} 
passou a atingir níveis mais profundos e a criar oportunidades de criação de laços entre as participantes. Com a experiência adquirida, o PET-SI decidiu elaborar atividades mais atrativas e de maior complexidade, projetando para 2020 a realização de atividades com programação para robôs e atividades no campus da universidade.

\section{Método}

Para que atividades extensionistas tenham um efeito positivo nas escolas de ensino fundamental, é preciso que elas sejam introduzidas na dinâmica escolar com muito planejamento. Por esse motivo, o contato com as escolas e o planejamento das atividades foram feitos com o apoio de profissionais da área de Educação que possuem vivência na interação universidades-escolas. No primeiro contato com as escolas, uma reunião é realizada para apresentar o projeto e às vezes para executar as atividades previstas para ocorrer com as alunas junto à direção e ao corpo docente. As opiniões da direção e de professores são coletadas para ajustar as atividades e são agendadas as visitas às escolas.

No dia da visita, as turmas são divididas em grupos de 15 a 20 alunas. A interação com elas se dá da seguinte forma. As universitárias se apresentam e propõem uma atividade de computação desplugada para as alunas. Atividades de computação desplugada foram escolhidas porque é um caminho para o ensino do pensamento computacional e de conceitos de computação sem o uso de recursos tecnológicos, inclusive de computadores, o que facilita a aplicação em qualquer condição de infraestrutura [Bell et al. 2011].

A atividade escolhida pelo PET-SI aborda o conceito de representação de imagens digitais e utiliza oito placas de papel rígido preto ou rosa, cobertas por quadrados removíveis de papel branco que contêm uma operação de matemática básica. Em grupos, as participantes devem retirar da placa apenas os papéis cujas operações resultam em números pares. Em seguida, as participantes unem as placas para montar uma imagem. Por fim, explica-se às participantes os conceitos de ciência da computação presentes na dinâmica (pixel, formação de imagens digitais e resolução de imagem) e com isso elas percebem que são capazes de entender conceitos que poderiam parecer complexos e inalcançáveis. A figura 3 traz imagens com exemplos das placas desmontadas e montadas.
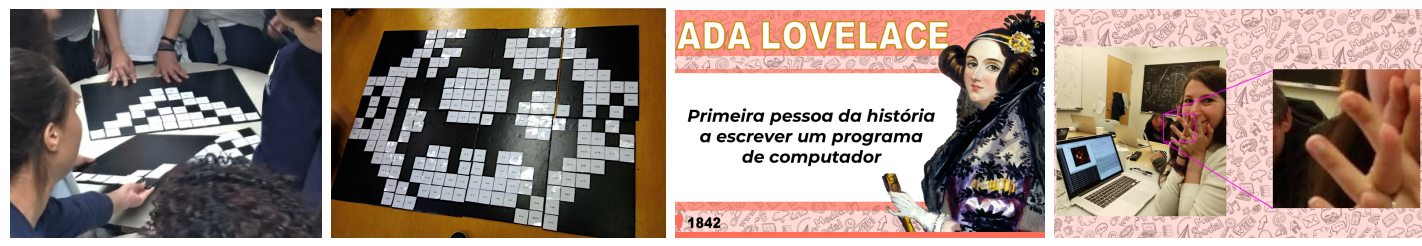

Figura 3. Placas usadas na atividade de computação desplugada (à esquerda) e slides usados na interação com as meninas (à direita)

Após a atividade de computação desplugada, o projeto GRACE faz uma apresentação às alunas e inicia uma conversa na qual as alunas são motivadas a se manifestar em relação ao seu conhecimento e posicionamento diante da área de Computação. Durante a conversa com as alunas, a discussão sobre disparidade de gênero é inserida aos poucos e de forma leve, tentando entender o contexto em que as alunas estão inseridas, expectativas para o futuro, e possíveis motivações e barreiras que percebem para seguir uma carreira em tecnologia. A apresentação possui seis partes: o que é computação; que 
tipo de trabalho é possível desenvolver como profissional da área; as mulheres que já desenvolveram trabalhos importantes e aquelas que hoje são destaques regionais, nacionais ou internacionais ${ }^{5}$; as professoras do curso de Sistemas de Informação na Universidade de São Paulo e suas pesquisas; as universitárias do projeto GRACE e suas expectativas para o futuro; sugestões sobre onde aprender mais sobre tudo o que foi discutido e dados de contato do projeto GRACE. A figura 3 ilustra dois dos slides usados na apresentação.

\section{Resultados e lições aprendidas}

Até o momento, o projeto GRACE visitou seis escolas e realizou dinâmicas com alunas de cinco delas. A tabela 1 mostra alguns resultados ${ }^{6}$ quantitativos das atividades com alunas de oitavo e nono anos ${ }^{7}$. O projeto GRACE também tem efeitos para quem o organiza e executa. Desta perspectiva, vale ressaltar, como resultado, o engajamento que o projeto conseguiu produzir dentro do âmbito da universidade. Ao todo, cerca de 12 alunas de graduação, três alunas de pós-graduação, uma egressa desses cursos e duas professoras já estiveram envolvidas, além dos 15 alunos da graduação e um professor do curso.

Tabela 1. Resultados quantitativos referente à interação com escolas

\begin{tabular}{c|c|c|c}
\hline Ano & \# visitas de apresentação & \# visitas de interação & \# alunas atendidas \\
\hline 2017 & 2 & - & - \\
2018 & 6 & 2 & 22 \\
2019 & 1 & 3 & 88 \\
\hline
\end{tabular}

As dinâmicas realizadas nas escolas permitiram ao grupo aprender algumas lições. A proposta do projeto GRACE e a oportunidade de colocar alunas adolescentes em contato com universitárias que se preparam para trabalhar com tecnologia é bem recebida pelos professores. Ainda, se há a oportunidade de realizar a dinâmica com os professores o resultado é melhor, pois eles sugerem alterações no roteiro de apresentação para ficarem mais compatíveis com o público-alvo da atividade.

$\mathrm{Na}$ interação com as alunas, o aprendizado adquirido confirma o problema cultural e a necessidade de manter e intensificar projetos como este. Nota-se que a introdução de atividades de matemática causa um desconforto em muitas delas, mas a surpresa referente à descoberta da imagem escondida nas placas desperta o interesse das meninas. Durante as conversas com as alunas, muitas vezes é necessário trazer as mais reclusas a participar das discussões e notou-se que o interesse de todas é despertado quando: (i) as universitárias colocam suas experiências pessoais; (ii) os feitos das mulheres na computação são mostrados; (iii) conhecem a diversidade de assuntos pesquisados pelas professoraspesquisadoras do curso de Sistemas de Informação na Universidade de São Paulo; (iv) percebem que conceitos matemáticos que aprendem na escola assumem uma utilidade prática e de menor complexidade do que elas imaginavam inicialmente; $(v)$ percebem a existência do problema de disparidade de gênero, transpõem esse problema para situações de suas próprias rotinas e percebem que situações similares ocorrem com outras pessoas.

\footnotetext{
${ }^{5} \mathrm{O}$ projeto GRACE insere na apresentação o trabalho de Katie Bouman e faz uma ligação com os conceitos ensinados na atividade de computação desplugada.

${ }^{6}$ Resultados das demais atividades do projeto GRACE estão fora do escopo desta discussão.

${ }^{7}$ Excepcionalmente, em uma das visitas de 2018 um grupo de oito mulheres participou de uma dinâmica.
} 
Importante ressaltar ainda que o projeto também tem efeito sobre as universitárias que visitam as escolas, que se sentem orgulhosas de seu trabalho e recompensadas por ele. Esse sentimento as estimula a continuarem o trabalho e também as fortalece para enfrentar novos desafios. O efeito é decorrente principalmente de dois pontos: $(i)$ por vezes, as pessoas nas escolas se mostram positivamente surpreendidas pela maturidade das universitárias que atuam no projeto; (ii) as alunas demonstram gratidão e admiração pelas universitárias, expressando esse sentimento pessoalmente e também pelas redes sociais.

\section{Considerações finais}

Para muitas das meninas atendidas pelo projeto GRACE, o conhecimento em computação como profissão se resume em ver amigos, conhecidos e familiares, na maioria homens, trabalhando em frente ao computador. Entrar em contato com a diversidade e importância das atividades relacionadas à Computação, como essa área pode ajudar a sociedade, e experimentar a computação em sua forma lúdica "abre a mente" dessas meninas e mostra a elas um caminho diferenciado que pode ser seguido de maneira prazerosa.

\section{Agradecimentos}

Os autores agradecem o apoio do Programa Aprender na Comunidade da Pró-Reitoria de Graduação da Universidade de São Paulo e do Programa PET do Ministério da Educação.

\section{Referências}

Bell, T., Ian H. Witten, I. H., and Fellows, M. (2011). Computer Science Unplugged.

Cimpian, J. R., Kim, T. H., and McDermott, Z. T. (2020). Understanding persistent gender gaps in stem. Science, 368(6497):1317-1319.

de Santana, B. S. and Pereira, C. P. (2019). Aproximação de alunas do ensino básico do pensamento computacional: relato de experiência de uma oficina de eletrônica. In Anais do Workshop de Informática na Escola, volume 25, page 69.

Maciel, C. and Bim, S. A. (2016). Programa meninas digitais - ações para divulgar a computação para meninas do ensino médio. In Anais Computer on the Beach. SBC.

Nunes, M. A., Louzada, C., Salgueiro, E., Andrade, B., de Lima, P., and Figueiredo, R. (2016). Mapeamento de iniciativas brasileiras que fomentam a entrada de mulheres na computação. In Anais do X Women in Information Technology, pages 56-60. SBC.

Peres, S. M., Boscarioli, C., Ferrari, A., Costa, C. I., Alves, C. M., Salles, C. G., Bruscatto, G., Silva, G. S., Silva, L. F., Souza, L. G., Teixeira, M. F., Delmondes, P. H. M., and Wagner, P. K. (2014). O programa de educação tutorial no contexto da graduação em computação: Perfis, percepções e reflexões. In XXII Workshop sobre Educação em Computação - Anais do XXXIV Congresso da SBC, pages 1503-1512. SBC.

Ribeiro, L., Barbosa, G., Silva, I., Coutinho, F., and Santos, N. (2019). Um panorama da atuação da mulher na computação. In Anais do XIII WIT, pages 1-10. SBC.

Torres, K. B. V., Bernardes, R. M., de Queiros, P. S., Vieira, T. M., Felix, J. C., De Urzedo, A. P. F. M., Souza, D. H. L., and Mendes, T. T. (2017). Inclusão das mulheres nas ciências e tecnologia: Ações voltadas para a educação básica. Expressa Extensão, 22(2):140-156. 